\title{
SISTEM PENGAMBILAN KEPUTUSAN PEMILIHAN LAHAN TANAM DI KABUPATEN WONOSOBO DENGAN K-MEANS CLUSTERING DAN TOPSIS
}

\author{
Khomsatun ${ }^{1}$, Dedy Ikhsan ${ }^{2}, \mathrm{M} \mathrm{Ali}^{3}$, Kusrini $^{4}$, \\ ${ }^{1}$ Magister Teknik Informatika, Univeristas Amikom Yogyakarta, Indonesia \\ e-mail: oonkhaura2@gmail.com¹, dedy.1147@students.amikom.ac.id², \\ muhamadali@students.amikom.ac.id ${ }^{3}$, kusrini@amikom.ac.id ${ }^{4}$
}

\begin{abstract}
Abstrak
Melakukan pemilihan lahan tanam pada suatu lahan yang akan ditanami dengan kriteria lahan tanam yang sesuai sangat diperlukan sebagai pendukung keputusan. Kesalahan dalam memilih lokasi lahan tanam yang tidak sesuai membuat menurunnya produksi kentang di Kabupaten Wonosobo. Di karenakan kurangnya informasi petani dalam memanfaatkan lahan kosong secara tepat untuk memilih lokasi lahan tanam yang sesuai untuk ditanami tanaman. Tujuan penelitian ini adalah untuk membantu para petani dalam menentukan lokasi lahan tanam yang sesuai dengan tanaman yang akan ditanam. Sehingga mampu meningkatkan produksi tanaman kentang di Kabupaten Wonosobo. Metode yang digunakan dalam penelitian ini K-Means Clustering akan mengelompokkan kecamatan dengan kriteria suhu dan Techniqeu for Order Preference by Similarity to Ideal Solution (TOPSIS) untuk perangkingan kecamatan yang terbaik. Kedua metode tersebut menghasilkan kecamatan mana yang sesuai dengan tanaman kentang pada Kabupaten Wonosobo. Pengujian dilakukan terhadap 5 kecamatan dari 10 kecamatan yang ada di Kabupaten Wonosobo dengan membandingkan hasil dari perhitungan manual dan sistem mendapatkan hasil akurasi terbaik 1,49 untuk kecamatan kejajar. Sistem ini sudah mampu memberikan rekomendasi untuk lahan tanam yang sesuai dengan cukup akurat.
\end{abstract}

Kata kunci: tanaman, K-Means, Topsis

\begin{abstract}
Choosing planting land on an area to be planted with suitable planting land criteria is very much needed as a decision support. Errors in choosing the location of planting land that is not suitable to make a decrease in potato production in Wonosobo Regency. Because of the lack of information farmers in right the use of vacant land to select the location of suitable planting land for planted crops. The purpose of this study is to assist farmers in determining the location of planting land in accordance with the plants to be planted. So that it can increase the production of potato plants in Wonosobo Regency. The method used in this study is K-Means Clustering will classify the diatoms by temperature criteria and Techniqeu for Order Preference by Similarity to Ideal Solution (TOPSIS) for the best sub-district ranking. Both methods produce which subdistricts are suitable for potato crops in Wonosobo District. Tests conducted on 5 districts of 10 districts in Wonosobo District by comparing the results of manual calculations and the system obtained the best accuracy of $1.49 \%$ for parallel districts. This system has been able to provide recommendations for suitable planting land enough quite accurately.
\end{abstract}

Keywords : plants, K-Means, Topsis 


\section{PENDAHULUAN}

Penggunaan teknologi informasi telah mengalami banyak perkembangan dan semakin kompleks dalam berbagai bidang, contohnya pada bidang pertanian. Perkembangan pada sektor pertanian tentu turut serta dalam membantu perkembangan ekonomi pada suatu daerah. Akan tetapi berdasarkan data statistik, lahan sawah terus menurun 7,75 juta hektar di 20177.100.000 hektar pada 2018, hal ini disebabkan sejumlah besar penggunaan lahan yang dirubah menjadi pabrik, bangunan, dan infrastruktur [1]. Di satu sisi ada masalah yang dihadapi oleh petani, yaitu kurangnya pemahaman suhu, ph tanah, dan curah hujan oleh petani yang dapat mempengaruhi hasil panen. Jadi dengan pemilihan tanaman yang tidak sesuai, maka tidak mendapatkan hasil yang optimal.

Masih banyak petani yang dalam melakukan pemilihan lokasi lahan tanam belum mengetahui dan memperhitungkan dengan tepat apakah tanah atau lahan tersebut sesuai untuk ditanami tanaman yang diinginkan, sehingga jika pada pemilihan lahan tanah di awal yang tidak produktif dan tidak sesuai, maka hasil panen akan mengalami kerugian yang cukup besar nantinya, faktor kondisi tanah pada lahan sangatlah penting dalam melakukan penanaman untuk hasil yang terbaik.

Dalam melakukan penelitian ini langkah-langkah yang dikerjakan adalah:
a. Perancangan (Design)
b. Pemilihan (Choice)
c. Membuat DSS

Diharapkan dengan adanya hasil penelitian ini dapat memberikan gambaran tentang pemanfaatan perkembangan teknologi informatika khususnya sistem pengambilan keputusan petani dalam memanfaatkan lahan kosong untuk di tanami kentang di Kabupaten Wonosobo.

Penelitian tentang penggunaan KMeans dan Topsis pernah dilakukan oleh Ahlihi Masruro, Kusrini, Emha Taufiq Luthfi dengan judul sistem penunjang keputusan penentuan lokasi wisata menggunakan KMeans Clustering dan topsis [2]. Dalam penelitian tersebut membahas tentang SPK pemilihan lokasi wisata dengan menerapkan kedua metode untuk sebuah informasi berupa daftar tempat wisata yang sesuai dengan tingkat kepentingan yang diharapkan oleh pengguna dari kriteria yang telah ditentukan terlebih dahulu. Adapun dalam penelitian ini SPK digunakan untuk menentukan lokasi kecamatan mana yang berpotensi ditanami kentang di Kabupaten Wonosobo.

Adapun jurnal Lianna Felicia dengan judul penerapan metode Clustering dengan K-Means untuk memetakan potensi tanaman padi di Kota Semarang [3] penelitian dilakukan pengklasteran daerah potensial penghasil padi menggunakan algoritma K-Means. Menggunakan KMeans bertujuan dalam memudahkan pengelompokan suatu daerah dengan hasil panen padi terbesar, sedang dan rendah. Hasilnya adalah sebuah gambaran yang menunjukan pengelompokan daerah berdasarkan hasil pertanian padi. Dalam penelitian ini K-Means digunakan untuk memilih lokasi yang tepat untuk di tanami kentang di Wonosobo.

Dalam penelitain Putrama Alkhairi, Agus Perdana Windarto, dengan judul penerapan K-Means Cluster pada daerah potensi pertanian karet produktif di Sumatera Utara [4]. Pengukuran dilihat dari hasil cluster dengan cara menghitung nilai kemurnian (purity measure) masing-masing cluster/kelompok yang di hasilkan. Data penelitian digunakan ialah data dari Badan Pusat Statistik (BPS) Provinsi Sumatera Utara. Tujuan penelitian bisa berkontribusi dalam mengefektifkan dalam penggunaan lahan pertanian karet pada setiap daerah. Penelitian ini memberikan solusi petani atau user dalam memilih lahan yang sesuai untuk di tanami kentang di daerah potensial.

Dalam penelitiannnya Nugroho Dwi Saksono , Yuita Arum Sari, Ratih Kartika Dewi [5], dengan judul rekomendasi lokasi wisata kuliner menggunakan metode $\mathrm{K}$ Means Clustering Dan Simple Additive Weighting menjelaskan tentang metode $\mathrm{K}$ Means Clustering akan membagi lokasi wisata sesuai jarak yang dihitung dari posisi awal user ke alamat lokasi wisata, lalu metode SAW akan mengurutkan lokasi 
mana yang paling sesuai dengan keinginan user. Data yang digunakan untuk pengujian menggunakan 49 data lokasi.

Penelitian Dema Mathias Lumban Tobing, Julia Kurniasih, Yulius Nahak Tetik, Kusrini, dengan judul Prototipe [6] sistem pendukung keputusan untuk memilih lahan tanaman. Dengan menggunakan metode TOPSIS dan penambahan sistem pakar untuk sistem pendukung keputusan, mengakibatkan pilihan alternatif tanah di sistem peringkat.

Mir. B. Aryanezhad, M.J. Tarokh, M.N. Mokhtarian \& F. Zaheri (2011), dalam penelitian mereka yang berjudul A Fuzzy TOPSIS Method Based on Left and Right Scores, menjelaskan berdasarkan fakta bahwa MCDM dalam dunia nyata sangat sulit untuk menentukan kesesuaian kreteria sesuai dengan yang diinginkan, sehingga mengusulkan penggunaan metode TOPSIS karena kesesuaian kreteria dinilai dari yang terdekat sesuai atau yang terjauh dari kesesuaian [7].

Keunggulan penelitian ini adalah menggabungkan antara data mining metode K-means clustering dan sistem pendukung keputusan metode TOPSIS secara gambling, mulai dari perolehan data dari BPS Kabupaten Wonosobo diteruskan dengan penetapan K-means disertai hitungan manual dan dilanjutkan perhitungan TOPSIS pada Cluster terpilih. Dengan ditampakkan visualisasi system melalui PHP Admin secara jelas disebutkan hasil tiap kecataman dengan masingmasing bobot yang dicapai. Penelitian ini juga dibuat karena adanya dasar kepedulian atas lahan tanam yang tidak dimanfaatkan sesuai dengan kriterianya.

\section{DSS (decision support systems)}

Sistem pengambilan keputusan merupakan sebuah sistem informasi interaktif yang menyediakan informasi, pemodelan, dan pemanipulasian data. Sistem itu digunakan untuk membantu pengambilan keputusan dalam situasi yang semiterstruktur dan tidak terstruktur, dimana tidak seorangpun tahu secara pasti bagaimana keputusan seharusnya dibuat [8]. Adapun penelitian ini metode yang digunakan adalah TOPSIS (The Technique for Order of Preference by Similarity to Ideal Solution). Metode ini mencari solusi dari data yang dimiliki dengan menampilkan hasil berdasarkan data terdekat nilai dengan keinginan dan nilai yang terjauh dari data yang diharapkan

\section{Clustering}

Clustering adalah teknik data mining yang digunakan untuk menganalisis dan mengkaji data untuk menyelesaikan permasalahan dalam pengelompokkan data membagi dari suatu dataset ke dalam subset. Teknik clustering tujuannya untuk kasus pendistribusian (orang, objek, peristiwa, dan lainnya) ke dalam suatu kelompok, hingga derajat keterkaiatan antara member cluster yang sama ialah lemah dan kuat antara anggota cluster dengan yang lainnya [9]. Teknik cluster mempunyai dua cara dalam pengelompokkan yaitu hierarchical clustering dan non-hierarchical clustering. Hierarchical clustering ialah metode mengelompokkan data yang kerjanya dengan cara mengelompokkan dua atau lebih data yang mempunyai kesamaan atau kemiripan, kemudian diteruskan ke objek lain yang mempunyai kedekatan dua, proses berlangsung sampai suatu cluster membentuk semacam tree dimana tingkatan atau hirarki yang jelas antar objek dari yang paling tidak mirip hingga yang paling mirip. Namun secara logika seluruh objek pada akhirnya akan membentuk sebuah cluster [10].

\section{Technique for Order Preference by Similarity to Ideal Solution (TOPSIS)}

Technique for Order Preference by Similarity to Ideal Solution (TOPSIS) adalah salah satu metode dari model keputusan MADM. Metode TOPSIS menggunakan konsep dimana alternatif terpilih yang terbaik tidak hanya memiliki jarak terpendek dari solusi ideal positif, tetapi juga memiliki jarak terpanjang dari solusi ideal negatif. Konsepnya sederhana, mudah dipahami, komputasinya yang efisien, dan memiliki kemampuan untuk mengukur kinerja relatif menjadikan metode ini banyak digunakan dalam model MADM [11]. Tahapan metode TOPSIS: 
a) Membuat matriks keputusan yang ternormalisasi

b) Membuat matriks keputusan yang ternormalisasi terbobot

c) Menentukan matriks solusi ideal positif dan matriks solusi ideal negatif

d) Menentukan jarak antara nilai setiap alternatif dengan matriks solusi ideal positif dan negatif

e) Menentukan nilai preferensi untuk setiap alternatif

\section{METODE}

1. Pengumpulan data

Data di peroleh penulis dari BPS (Badan Pusat Statistik). Penulis menggunakan data Suhu, $\mathrm{Ph}$ tanah, dan curah hujan yang terdapat pada Kabupaten Wonosobo.

\section{Perancangan Sistem}

Model perancangan menjelaskan mengenai cara kerja sistem ini. Terdapat beberapa proses utama yaitu input, proses, dan output. User akan menginput data lokasi lahan tanah dan bobot kriteria. Data tersebut akan diproses sistem menggunakan metode K-Means Clustering dan TOPSIS. Setelah dilakukan perhitungan, output akan menampilkan rekomendasi lokasi lahan tanah yang sudah diproses. Perancangan alur dari pemilihan lokasi lahan tanah akan dapat dilihat pada Gambar 1.

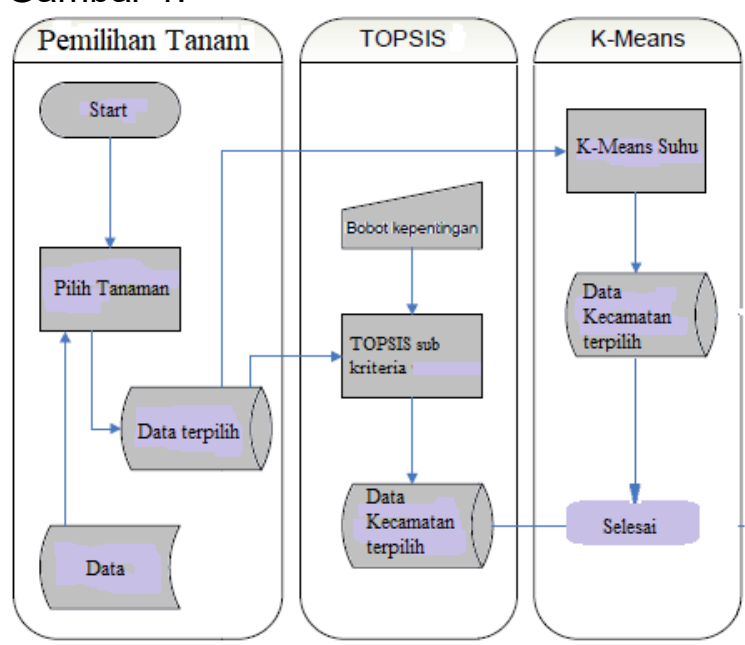

Gambar 1. Alur rancangan program
Pada penelitain ini menggunakan metode TOPSIS I dan II untuk memberikan hasil lahan tanah dalam suhu, sedangkan penelitian ini, menggunakan model sistem yaitu K-Means dan TOPSIS (Technique for Order Performance by Similarity to Ideal Solution). Dalam melakukan metode KMeans akan memberikan nilai yang akan diolah kembali oleh TOPSIS. Terdapat acuan mulainya proses dari pemilihan kriteria sampai didapatkan informasi lokasi lahan tanah.

Penerapan K-means Clustering dalam pengelompokkan kecamatan yang sesuai dengan tanaman kentang dengan penerapan suhu yang bagus dan tumbuh sempurna. Dengan Pengetahuan jika suhu diatas $25^{\circ} \mathrm{C}$ maka, tanaman kentang daunnya kecil dan umbinya tidak sempurna. Sedangkan kentang akan hidup bagus di antara suhu $15-22^{\circ}$ C. Karena tanaman kentang membutuhkan suhu yang berbeda tiap perkembangannya, maka suhu optimal adalah $18-20^{\circ}$ C. Dengan dasar pengetahuan ini, maka dibuat tahapan clustering menjadi 3 kelompok agar memudahkan dalam proses. Tahapan Kmeans Cluster adalah sebagai berikut :

1. Data set awal suhu tiap kecamatan

Table 1. Data set suhu tiap kecamatan

\begin{tabular}{|c|c|c|c|}
\hline Kecamatan & suhu & Langkah 1 & \\
\hline Wadaslintang & 26 & Jumlah Cluster & : \\
\hline Kejajar & 15 & Delta & : \\
\hline Sapuran & 17 & Min & : \\
\hline Garung & 15 & Max & : \\
\hline Kaliwiro & 25 & Toleransi Eror & : \\
\hline Sukoharjo & 24 & & \\
\hline Selomerto & 20 & C1 & : \\
\hline Mojotengah & 18 & $\mathrm{C} 2$ & : \\
\hline Wonosobo & 18 & C3 & : \\
\hline Kalikajar & 20 & & \\
\hline
\end{tabular}

\section{HASIL DAN PEMBAHASAN}


1) Dataset awal yang diperoleh

2. Iterasi 1

Table 2. Hasil perhitungan iterasi 1 dengan jarak antar kelas

\begin{tabular}{lccccc}
\hline \multirow{2}{*}{ Kecamatan } & suhu & \multicolumn{3}{c}{ Jarak dengan Kelas } & \multirow{2}{*}{ Kelas } \\
\cline { 3 - 6 } & & $\mathbf{1}$ & $\mathbf{2}$ & $\mathbf{3}$ & \\
\hline Wadaslintang & 26 & 9.17 & 5.50 & 1.83 & $\mathbf{3}$ \\
Kejajar & 15 & 1.83 & 5.50 & 9.17 & $\mathbf{1}$ \\
Sapuran & 17 & 0.17 & 3.50 & 7.17 & $\mathbf{1}$ \\
Garung & 15 & 1.83 & 5.50 & 9.17 & $\mathbf{1}$ \\
Kaliwiro & 25 & 8.17 & 4.50 & 0.83 & $\mathbf{3}$ \\
Sukoharjo & 24 & 7.17 & 3.50 & 0.17 & $\mathbf{3}$ \\
Selomerto & 20 & 3.17 & 0.50 & 4.17 & $\mathbf{2}$ \\
Mojotengah & 18 & 1.17 & 2.50 & 6.17 & $\mathbf{1}$ \\
Wonosobo & 18 & 1.17 & 2.50 & 6.17 & $\mathbf{1}$ \\
Kalikajar & 20 & 3.17 & 0.50 & 4.17 & $\mathbf{2}$ \\
\hline
\end{tabular}

3. Rerata tiap kelas

Table 3. Jarak rerata centroid tiap kelas

\begin{tabular}{rrrr}
\hline Kelas & Rerata & centroid & \multicolumn{1}{c}{$\begin{array}{c}\text { Rerata- } \\
\text { Centroid }\end{array}$} \\
\hline 1 & 17 & 16.83 & 0.233333 \\
2 & 20 & 20.5 & 0.5 \\
3 & 25 & 24.17 & 0.833333 \\
\hline \multicolumn{3}{r}{} & \\
\cline { 3 - 4 } & & &
\end{tabular}

4. Cluster yang didapat

Table 4. Hasil cluster kecamatan

\begin{tabular}{cl}
\hline Cluster & \multicolumn{1}{c}{ Kecamatan } \\
\hline 1 & Kejajar, Sapuran, Garung, Mojotengah, \\
2 & Selomosobo \\
3 & Wadaslintang, Kalikajar \\
\hline
\end{tabular}

Proses K-means selesai dalam proses ini dengan hasil kelompok 1 adalah daftar kecamatan yang bisa ditanami kentang dan hidup bagus di Kabupaten Wonosobo, yang selanjutnya beralih ke proses TOPSIS guna mendapatakan kecamatan mana yang lebih optimal.

Proses Topsis data ditentukan perhitungan manual sebagai berikut :
Table 5. Data set cluster terpilih guna Topsis tanaman

\begin{tabular}{lrrr}
\hline Kecamatan & \multicolumn{1}{c}{$\begin{array}{c}\text { Suhu } \\
\text { (C1) }\end{array}$} & $\begin{array}{c}\text { pH Tanah } \\
\text { (C2) }\end{array}$ & $\begin{array}{l}\text { Curah } \\
\text { hujan } \\
\text { (C3) }\end{array}$ \\
\hline Kejajar & 15 & 6 & 357 \\
Sapuran & 17 & 6 & 369 \\
Garung & 15 & 7 & 364 \\
Mojotengah & 18 & 6 & 435 \\
Wonosobo & 18 & 6.5 & 346 \\
\hline
\end{tabular}

2) Penentuan bobot oleh user dengan table bantu

Table 6. Bobot dan kriteria topsis tanaman

\begin{tabular}{llr}
\hline Kriteria & Kondisi & Nilai \\
\hline SUHU & sangat & 5 \\
PH TANAH & penting & 4 \\
CURAH HUJAN & cukup penting & 3 \\
\hline
\end{tabular}

3) Tahap 1 matrik keputusan ternormalisasi

* Suhu (C1)

$\mathrm{X}_{1}=\sqrt{\text { nilai kec }}$ Kejajar $^{2}+\ldots^{2}+\ldots^{2}$ $+\ldots{ }^{2}+\ldots{ }^{2}=37.24$

- Ph Tanah (C2) $\mathrm{X}_{1}=\sqrt{ }$ nilai kec $\mathrm{Kejajar}^{2}+\ldots^{2}+\ldots{ }^{2}$ $+\ldots{ }^{2}+\ldots{ }^{2}=14,12$

- Curah HUjan (C3) $\mathrm{X}_{1}=\sqrt{ }$ nilai kec Kejaja ${ }^{2}+\ldots^{2}+\ldots{ }^{2}$ $+\ldots^{2}+\ldots^{2}=839,67$

Sehingga didapat nilai dari tiap kecataman nilai didapat dengan rumus nilai kriteria di kecamatan dibagi dengan nilai tiap matrik. Kejajar $=15 / 37.24=0,40 \ldots$ dst

Table 7. Hasil matrik keputsan normalisasi

\begin{tabular}{lrrr}
\hline Tahap 1 & $\begin{array}{c}\text { Suhu } \\
\text { (C1) }\end{array}$ & \multicolumn{1}{c}{$\begin{array}{c}\text { pH Tanah } \\
\text { (C2) }\end{array}$} & $\begin{array}{c}\text { Curah } \\
\text { hujan } \\
\text { (C3) }\end{array}$ \\
\hline & $\mathbf{3 7 . 2 4}$ & $\mathbf{1 4 . 1 2}$ & $\mathbf{8 3 9 . 6 7}$ \\
Kejajar & 0.40 & 0.43 & 0.43 \\
Sapuran & 0.46 & 0.43 & 0.44 \\
Garung & 0.40 & 0.50 & 0.43 \\
\hline
\end{tabular}




\begin{tabular}{llll}
\hline Mojotengah & 0.48 & 0.43 & 0.52 \\
Wonosobo & 0.48 & 0.46 & 0.41
\end{tabular}

4) Tahap 2 yaitu : matriks keputusan terbobot

* Suhu (C1)

Kejajar $=w_{1}{ }^{*} r_{11}=$ bobot suhu yang ditentukan user*nilai yang dimiliki kecamatan pada tahap 1= 5 * $0,40=2,01 \ldots . d s t$

* Ph Tanah (C2)

Kejajar $=w_{1} * r_{11}=$ bobot $\mathrm{Ph}$ Tanah yang ditentukan user*nilai yang dimiliki kecamatan pada tahap $1=4$ * $0,43=1,7 \ldots$ dst

* Curah Hujan (C3)

Kejajar $=\mathrm{w}_{1}{ }^{*} \mathrm{r}_{11}=$ bobot Curah Hujan yang ditentukan user*nilai yang dimiliki kecamatan pada tahap $1=3 * 0,43=1,28$, dst...

Table 8. hasil matrik terbobot

\begin{tabular}{lrrr}
\hline Tahap 2 & $\begin{array}{c}\text { Suhu } \\
\text { (C1) }\end{array}$ & $\begin{array}{c}\text { pH Tanah } \\
\text { (C2) }\end{array}$ & $\begin{array}{c}\text { Curah hujan } \\
\text { (C3) }\end{array}$ \\
\hline Kejajar & 2.01 & 1.70 & 1.28 \\
Sapuran & 2.28 & 1.70 & 1.32 \\
Garung & 2.01 & 1.98 & 1.30 \\
Mojotengah & 2.42 & 1.70 & 1.55 \\
Wonosobo & 2.42 & 1.84 & 1.24 \\
\hline
\end{tabular}

5) Tahap 3 menentukan solusi Ideal negatife dan Positif

Table 9. Solusi ideal positif dan negatif

Solusi ideal

Positif

\begin{tabular}{|c|c|c|c|}
\hline & $\begin{array}{l}\text { Suhu } \\
\text { (C1) }\end{array}$ & $\begin{array}{l}\text { pH Tanah } \\
\text { (C2) }\end{array}$ & $\begin{array}{l}\text { Curah hujan } \\
\text { (C3) }\end{array}$ \\
\hline Nilai & Max & Max & Min \\
\hline$A+$ & 2.42 & 1.98 & 1.24 \\
\hline
\end{tabular}

Solusi ideal

Negatif

\begin{tabular}{|l|l|l|l|}
\hline & $\begin{array}{l}\text { Suhu } \\
(\mathrm{C} 1)\end{array}$ & $\begin{array}{l}\mathrm{pH} \text { Tanah } \\
(\mathrm{C} 2)\end{array}$ & $\begin{array}{l}\text { Curah hujan } \\
(\mathrm{C} 3)\end{array}$ \\
\hline Nilai & Min & Min & max \\
\hline A- & $\mathbf{2 . 0 1}$ & $\mathbf{1 . 7 0}$ & \\
\hline
\end{tabular}

6) Tahap 4 menentukan jarak antara nilai setiap alternatif dengan matriks solusi ideal positif dan matriks.

Table 10. Hasil jarak antara idea

\begin{tabular}{llll}
\hline Ideal Positif & \multicolumn{3}{l}{ Idea Negatif } \\
\hline Kejajar & 0.49 & Kejajar & 0.28 \\
Sapuran & 0.32 & Sapuran & 0.36 \\
Garung & 0.41 & Garung & 0.38 \\
Mojotengah & 0.43 & Mojotengah & 0.40 \\
Wonosobo & 0.14 & Wonosobo & 0.53 \\
\hline
\end{tabular}

7) Penentu tiap nilai kecamatan, Menentukan nilai preferensi untuk setiap alternative

Table 11. Hasil TOPSIS kentang tiap kecamatan

\begin{tabular}{ll}
\hline Kejajar & 1.49 \\
Sapuran & 1.32 \\
Garung & 1.41 \\
Mojotengah & 1.43 \\
Wonosobo & 1.14 \\
\hline MAX & $\mathbf{1 . 4 9}$ \\
\hline
\end{tabular}

Ditemukan kecamatan dengan nilai max yaitu Kecamatan Kejajar. Dengan SPK ini ditemukan Kecamatan Kejajar yang mempunyai peluang terbesar kentang itu tumbuh dan berkembang optimal dengan penekanan pada suhu yang bagus dan didukung oleh curah hujan serta Ph tanah yang memadai sesuai dengan keiteria yang ditentukan.

Tampilan menu dalam SPK

$$
\text { 1. Halaman awal }
$$

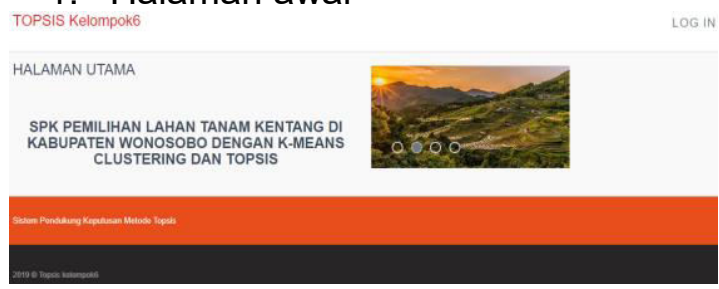

Gambar 2. Halaman awal

2. Login SPK 


\section{Gambar 7. Normalisasi matriks kecamatan}

7. Matriks terbobot

Normalisasi Matrik:

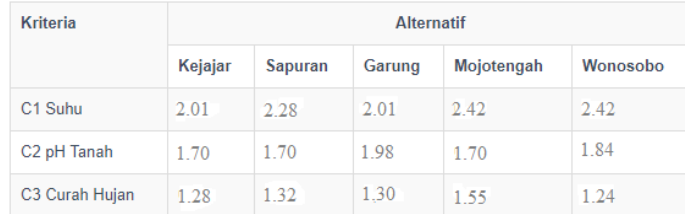

Gambar 8. Matriks terbobot kecamatan

8. Jarak antara nilai bobot (ideal solusi negatif dan positif)

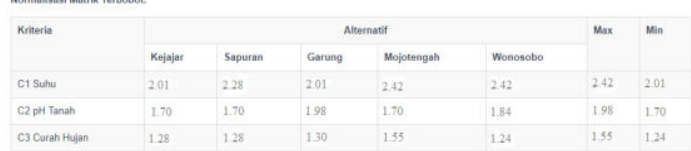

Gambar 9. Jarak Ideal positif dan negative

9. Kedekatan alternative tiap alternatife

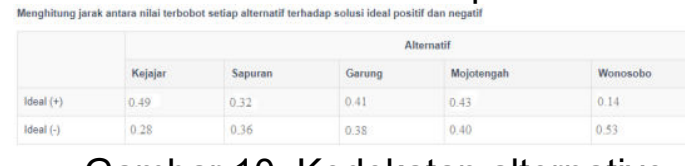

Gambar 10. Kedekatan alternative

10. Hasil urutan terbesar dan terkecil dalam proses Topsis

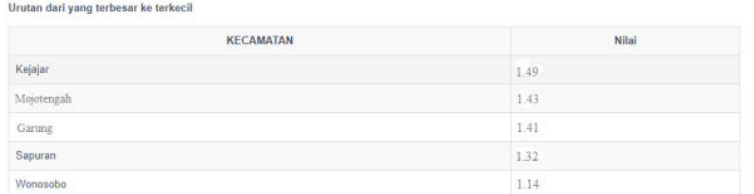

Gambar 11. Tampilan hasil topsis

Menguji kebenaran dari proses kerja sistem dilakukan dengan membandingkan hasil perhitungan secara manual dengan hasil perhitungan sistem. Hasil pengujian menunjukkan nilai perhitungan secara manual sama dengan perhitungan sistem, perbandingan hasil dapat dilihat pada Tabel 11.

\section{SIMPULAN}

Berdasarkan hasil perancangan, implemetasi, dan pengujian sistem yang dilakukan oleh penelitian sistem pengambilan keputusan pemilihan lahan tanam di kabupaten wonosobo dengan kmeans clustering dan topsis ini dapat di tarik kesimpulan sebagai berikut. 
1. Sistem pengambilan keputusan pemilihan lahan tanam di Kabupaten Wonosobo dengan K-Means Clustering dan Topsis dapat diselesaikan dengan teknik data mining dan SPK menggunakan aturan Clustering untuk mengelompokkan daerah potensial tanaman kentang.

2. Dalam sistem pengambil keputusan dengan menggunakan motode Topsis ini menghasilkan urutan rekomendasi kecamatan terbaik untuk lahan tanam yang sesuai di Kabupaten Wonosobo. Ditentukan ataupun bisa dipilih menurut kebutuhan dengan bobot dan kriteria juga bisa menyesuaiakan.

3. Hasil dari pengujian ini bahwa dalam perangkingan kecamatan potensi tanaman kentang cara manual memiliki hasil yang sama dengan hasil sistem yang dibuat dengan kecamatan kejajar dengan nilai rekomendasi terbaik yaitu 1,49 dengan hasil ini berarti penelitian layak dan berhasil.

Saran untuk penelitian selanjutnya diharapkan adanya penambahan tanaman lain di daerah Wonosobo seperti purwaceng, carica, kopi, duren, duku, dll. Penelitian ini juga bisa diterapkan di daerah selain di Kabupaten Wonosobo yang memiliki lahan yang kurang sesuai dalam penanaman hasil perkebunan dan pertanian.

\section{UCAPAN TERIMAKASIH}

Terima kasih diucapkan kepada Universitas Amikom Yogyakarta yang telah mendukung secara moral atau materil demi terselesaikanya penelitian ini.

\section{REFERENSI}

[1] CNN Indonesia, "BPS Sebut Luas Lahan Pertanian Kian Menurun," Accessed June 28, 2019. https://www.cnnindonesia.com/ekonomi/ 20181025153705-92- 341433/bpssebut-luas-lahan-pertanian-kianmenurun.

[2] Ahlihi Masruro, Kusrini, Emha Taufiq Luthfi, Sistem Penunjang Keputusan
Penentuan Lokasi Wisata

Menggunakan K-Means Clustering Dan Topsis, Jurnal IImiah DASI Vol. 15 No. 04 Desember 201, hlm 1 - 5, ISSN: 1411-3201

[3] Lianna Felicia, Penerapan Metode Clustering Dengan K-Means Untuk Memetakan Potensi Tanaman Padi Di Kota Semarang

[4] Putrama Alkhairi, Agus Perdana Windarto, Penerapan K-Means Cluster Pada Daerah Potensi Pertanian Karet Produktif di Sumatera Utara, ISBN: 978602-52720-1-1, Januari 2019Hal: 762 767

[5] Nugroho Dwi Saksono , Yuita Arum Sari, Ratih Kartika Dewi, Rekomendasi Lokasi Wisata Kuliner Menggunakan Metode K-Means Clustering Dan Simple Additive Weighting, Jurnal Pengembangan Teknologi Informasi dan IImu Komputer e-ISSN: 2548-964X Vol. 2, No. 10, Oktober 2018, hlm. 3835-3842 http://j-ptiik.ub.ac.id.

[6] Dema Mathias Lumban Tobing, Julia Kurniasih, Yulius Nahak Tetik, Kusrini, Prototipe Sistem Pendukung Keputusan Untuk Memilih Lands Tanaman,

[7] Mir. B. Aryanezhad, M.J. Tarokh, M.N. Mokhtarian \& F. Zaheri, A Fuzzy TOPSIS Method Based on Left and Right Scores, Internasional Journal OF Industrial Enginering \& Production Reseach, 2011

[8] Kusrini, Konsep dan Aplikasi Pendukung Keputusan, Andi Yogyakarta, 2007

[9] Solikhun, A. P. Windarto, Handrizal, and M.Fauzan, "Jaringan Saraf Tiruan Dalam Memprediksi Sukuk Negara Ritel Berdasarkan Kelompok Profesi Dengan Backpropogation Dalam Mendorong Laju Pertumbuhan Ekonomi," Kumpul. J. Ilmu Komput., vol. 4, no. 2, pp. 184-197, 2017

[10] J. Informatika, W. Mega, and P. Dhuhita, "Clustering Menggunakan Metode K-Means Untuk," vol. 15, no. 2, 2015.

[11] Kusumadewi, Sri, dkk. 2006. Fuzzy MultiAttribute Decision Making (Fuzzy MADM).Yogyakarta : Graha IImu. 
[12] https://www.anakagronomy.com/2014 /12/syarat-tumbuh-tanaman-kentangsolanum.html 